\title{
Aspectos culturales en los manuales de E/LE destinados a alumnos de español fuera de sus fronteras lingüísticas: El caso de los manuales de español para argelinos
}

\author{
RACHID NADIR \\ Universidad Amar Télidji de Laghouat \\ r.nadir@lagh-univ.dz \\ MAR GutiéRrez-Colón PlanA \\ Universitat Rovira i Virgili \\ mar.gutierrezcolon@urv.cat \\ MARCIÀ RIUTORT \\ Universitat Rovira i Virgili \\ marcia.riutort@urv.cat
}

\begin{abstract}
Resumen: El objetivo de este estudio es la elaboración de los parámetros que deberían reunir los manuales de E/LE cuando sus destinatarios son alumnos de español de fuera de las fronteras lingüísticas españolas. La hipótesis principal es que el mejor manual debería enseñar a la vez la lengua española y la cultura española. Para ello se ha creado un corpus a partir de los cinco manuales de E/LE que actualmente se destinan a la enseñanza de español como lengua extranjera en el Instituto Cervantes de Argelia; se ha determinado lo culturalmente explícito e implícito; se ha analizado hasta qué punto los culturemas detectados se enseñan de un modo directo o indirecto; cuándo son inocuos y cuándo chocan con los correspondientes culturemas argelinos. Los resultados concluyen que los manuales actuales no contemplan las diferencias lingüísticas, pragmáticas o culturales del alumnado argelino. Proponemos la necesidad de editar manuales específicos para cada cultura.
\end{abstract}

Palabras clave: manuales de E/LE, aspectos culturales, enseñanza del español, Instituto Cervantes, español en Argelia.

\section{Cultural aspects in the manuals of Spanish as a Foreign Language for abroad students: The case of Spanish manuals for algerians}

Abstract: The aim of this study is to develop the parameters that should meet manuals E/LE when the students of Spanish language are outside the Spanish language boundaries. The main hypothesis is that the best manual should teach both the Spanish language and the Spanish culture. This research study has created a corpus from the five manuals of Spanish as a Foreign Language. These manuals are the ones used to teaching SFL in the Cervantes Institute of Algeria. The research determines what is culturally explicit and implicit; it also analyzes the extent to which detected culturemes are taught directly or indirectly; when they are correct and when they collide with the corresponding Algerian culturemes. The results conclude that current manuals do not include linguistic, pragmatic or cultural differences of the Algerian students. We propose the need to edit specific manuals for each culture. 
Key words: manuals of E/LE, cultural aspects, teaching Spanish, Instituto Cervantes, Spanish in Algeria.

\section{Introducción}

El objetivo de este estudio es la elaboración de los parámetros que deberían reunir los manuales de E/LE cuando sus destinatarios son alumnos de español de fuera de las fronteras lingüísticas españolas. La hipótesis principal es que el mejor manual debería enseñar a la vez la lengua española y la cultura española, a partir de una contrastación de los culturemas españoles con los correspondientes culturemas de la cultura de uso del manual.

Para la realización de este estudio nos hemos servido del análisis de múltiples estudios sobre la adquisición de lenguas extranjeras, en relación con el análisis de manuales de E/LE. De esta primera investigación se desprende que hasta el momento aún existen pocos estudios destinados a países magrebíes, como es el caso de Argelia, y ninguno que trate de adaptar los culturemas hispanos que aparecen en los manuales de E/LE, entendiendo por culturemas toda manifestación cultural que identifica a una comunidad.

En el caso que nos ocupa, los manuales utilizados en Argelia han sido elaborados por dos editoriales españolas. La primera es «la editorial de las empresas SM, dedicadas a la elaboración de contenidos y servicios educativos, publicaciones religiosas, y literatura infantil y juvenil; y la labor social de la Fundación SM, que destina los beneficios del grupo editorial a mejorar la calidad de la educación y a hacer llegar la docencia y la cultura a los sectores más desfavorecidos de la sociedad» ${ }^{1}$, cita de la cual se desprende que esta editorial ha elaborado sus manuales desde la perspectiva universalista, sin adaptarlos a las necesidades del país destinatario. Esto, por tanto, coincide con lo que afirma Rodríguez Garrido (2005: 74), cuando dice que muchas de las editoriales encargadas de elaborar este tipo de manuales no están especializadas en E/LE. La segunda es la Editorial Difusión, especializada tanto en E/LE como en otras lenguas extranjeras.

\section{Los argelinos y los españoles, ¿tan cerca o tan lejos?}

Intentar hallar una definición precisa del término «cultura» es una misión difícil, por no decir casi imposible de alcanzar. Queda claro que no existe una sola definición del concepto con carácter normativo o que nos convenza a todos, tal vez porque, como dice García Pilar (1999: 113):

En la definición de cultura interviene un número de componentes: el medio ambiente (países del norte frente a los del sur, entornos naturales, climatología, etcétera); la psique proyectada, formada por mitos, cuentos, creencias, supersticiones, ritos; los elementos conductuales, como ceremonias, prácticas, creencias mágico-religiosas; el nivel de desarrollo; las relaciones familiares; la lengua, etcétera.

Dada la amplitud del concepto de cultura, sin embargo, en este artículo intentaremos abordar el concepto de "cultura" en la enseñanza y aprendizaje del español como lengua extranjera (E/LE) desde dos puntos de vista:

En primer lugar, como:

${ }^{1}$ http://www.grupo-sm.com/grupo-sm [fecha de consulta: 30/08/2015]. 
Una serie de hábitos compartidos por los miembros de un grupo que vive en un espacio geográfico, aprendidos, pero condicionados biológicamente, tales como los medios de comunicación (de los cuales el lenguaje es la base), las relaciones sociales a diversos niveles, las diferentes actividades cotidianas, los productos de ese grupo y cómo son utilizados, las manifestaciones típicas de las personalidades, tanto nacional como individual, y sus ideas acerca de su propia existencia y la de los otros miembros (Poyatos Fernando, 1994: 25).

Es decir, analizaremos cuáles de estos componentes tratan los elaboradores de manuales de E/LE, dirigidos a los alumnos argelinos, y si reflejan -de verdad o no- la cultura actual española y la de los países de habla hispana.

En segundo lugar, se aborda el concepto de cultura no sólo como un conocimiento, de la cultura española e hispanohablante, necesario en el aprendizaje del español como lengua extranjera, sino también como un elemento importante que incorpora los aspectos culturales del estudiante argelino a la hora de enfrentarse a la cultura española.

Cuando hablamos de cultura y lengua de un país aludimos a dos conceptos unidos, de modo que la mayor parte del lenguaje está comprendida en la cultura, con lo que la lengua de una sociedad es un aspecto de la misma (García Pilar, 1999: 115).

La lengua es parte integrante del conjunto que constituye cualquier cultura. Por lo tanto, podemos decir que el conocimiento de esta lengua no es el fin ni el objetivo del aprendizaje, sino el medio que nos permite, entre otras cosas, acceder, comprender y luego vivir y sentir su cultura. El Marco Común Europeo (2002: epígrafe 5.1.1.2), considera que:

El conocimiento de la sociedad y de la cultura de la comunidad o comunidades en las que se habla el idioma es un aspecto del conocimiento del mundo" que "sin embargo, tiene la importancia suficiente como para merecer la atención del mundo, sobre todo porque, al contrario que muchos otros aspectos del conocimiento, es probable que no se encuentre en su experiencia previa y puede que esté distorsionado por los estereotipos.

Pottier Bernard (1993: 38) dice que «los misterios de la religión o la mitología van acompañados de la distancia en la comprensión de la lengua», es decir, la religión es uno de los fenómenos que influyen en la lengua. Parece claro, según Byram (1989: 40): «first there is the fact that language, and language variety - dialect or sociolect - is one of the overt signs of cultural identity which people meet daily in their lives», que se refiere a que la cultura es un saber compartido y negociado entre personas, es decir, que cualquier grupo tiene una cultura (Morte Barceló, 2003-2005: 10). Hoy en día, ya sea para los que se dedican a la didáctica de segundas lenguas, ya sea para los profesores de lengua, es evidente que lengua y cultura constituyen una especie de binomio indisoluble, y vienen a ser la cara y la cruz de una misma moneda: la lengua es vehículo y al mismo tiempo manifestación de cultura (Rodríguez Abella, 2000-2004: 1).

La religión predominante en Argelia es el Islam y casi el 99\% de la población es musulmana, por lo que gran parte de su cultura se ve influida por esta religión. Como todos los musulmanes del mundo, los argelinos celebran dos eventos religiosos muy importantes. Las dos fiestas están relacionadas con dos grandes pilares, con el más alto grado devocional en el Islam. La primera es la fiesta del Desayuno, con la que finaliza una adoración durante el mes de Ramadán, durante el cual se realizan buenas acciones, ayudando a los pobres con dinero y comida, además de la devoción del Ayuno. Setenta días después tiene lugar la segunda fiesta, la del Sacrificio. Los españoles celebran muchas fiestas durante todo el año. Una de las más importantes del año, que se celebra en todas las ciudades y pueblos de España, es la Semana Santa que celebran tanto los 
creyentes como las personas que no lo son. Debemos recordar aquí que hay fiestas a nivel estatal, otras que son regionales, y otras locales.

De todo lo citado, se desprende que los autores insisten sobre la importancia de incorporar los aspectos culturales y los culturemas del mundo de habla hispana en el proceso de aprendizaje/adquisición de la lengua española (como L2/LE), sobre todo sin hacer éstos el único contenido en otro material didáctico. Pero no tienen en cuenta a los alumnos que no están inmersos, ya tienen un pre conocimiento de otra lengua y de otra cultura totalmente distintas de la que están adquiriendo. De hecho, debemos mirar con una nueva perspectiva el concepto de cultura/culturemas y su incorporación en los manuales de E/LE o EL2, y no limitarnos a incorporar los aspectos culturales/culturemas del mundo de habla hispanohablante en los manuales, sino que es preciso incorporar los propios del alumno, integrando estrategias que le faciliten la identificación de lo que es suyo y lo que no lo es, el desarrollo de su papel intermediario cultural entre su propia cultura y la cultura que está aprendiendo/adquiriendo, para evitar posibles problemas causados por los contrastes culturales.

En resumen, podemos decir que el conocimiento de la vida diaria, las relaciones personales y las convenciones en los ámbitos público y privado, son fundamentales para el aprendiz del español. Conocer y respetar sus valores y creencias, así como su comportamiento ritual es esencial, máxime si se pretende desarrollar una conciencia intercultural que ayude al estudiante a aproximarse a la cultura meta sin prejuicios (Navarro Gómez, 2006-2008: 11).

\section{Estudios precedentes}

En la actualidad, los manuales de enseñanza de lenguas extranjeras no transmiten los mensajes de un modo único y simple. En este sentido, se ha podido constatar que uno de los más utilizados y que ha experimentado un notable crecimiento es el que se basa en el uso de textos que incluyen imágenes, dibujos y/o documentos icónicos. Y es por ello que, hoy en día, son muchos los investigadores interesados en este fenómeno, que se fijan en el contenido para analizar no sólo el texto y los gráficos sino también las ideas expresadas y transmitidas en ellos.

A continuación, presentamos, aunque sea de manera breve, algunos de los estudios con los que hemos trabajado, cuyo objetivo es analizar algunos aspectos de algunos manuales de español como lengua extranjera:

Ares Alida (2008) menciona algunos estudios sobre el tema de los materiales didácticos y la explotación de los textos en la enseñanza/aprendizaje de E/LE. Habla de las aportaciones relevantes de las disciplinas y corrientes teóricas que han contribuido a transformar el campo de la didáctica de LE y L2; para ello, la autora examina las investigaciones sobre adquisición $\mathrm{y}$ aprendizaje de segundas lenguas y lenguas extranjeras (ASL), y su relevancia para la didáctica, y resume la transformación metodológica operada en las últimas décadas en la lingüística educativa respecto a la E/LE y al uso de los textos en el aula, y la importancia del enfoque comunicativo y la enseñanza mediante tareas. Por su parte, Rodríguez Garrido (2005) habla de tipos de dificultades a la hora de dar clases de español a extranjeros, y del problema de «seleccionar el material apropiado sin tener una formación específica y sin apoyarse en una metodología concreta» (Rodríguez Garrido, 2005: 64). En la misma línea, Baralo Marta (2003) reflexiona sobre lo que ofrecen los materiales didácticos al estudiante de 
español como lengua extranjera. Su artículo concluye mencionando el valor que para el profesor deben tener los «criterios psicolingüísticos al diseñar su clase de E/LE, en relación a los materiales didácticos y su utilización» (Baralo Marta, 2003). Bernao Rueda (1994) estudia cuatro manuales de enseñanza de español como lengua extranjera siguiendo los criterios y pautas planteadas en Modern Languages for Communication $(M L f C)$, publicado por el Departamento de Educación del estado de Nueva York (1987) (Bernao Rueda, 1994: 79). A partir de este estudio, el autor intenta «ofrecer una descripción sistemática de los manuales para que el profesor de español, conociéndolos un poco, pueda acudir al que más le interese según los objetivos que persiga en cada momento a lo largo de su labor docente» (Bernao Rueda, 1994: 101). García Salazar (2004) ofrece una perspectiva crítica sobre los principales procedimientos para la selección objetiva de los contenidos léxicos a la hora de elaborar materiales didácticos específicos para la enseñanza de las segundas lenguas. Cita tres criterios que considera que son importantes en la selección objetiva y sobre todo para elaborar materiales de LE: la frecuencia, el uso y la disponibilidad. Bani Sara y Nevado Almudena (2004) estudian el tratamiento de elementos lingüísticos como los pronombres personales, el condicional y el imperativo para comprobar si hacen referencia al concepto de cortesía expresado en algunos manuales de español para extranjeros. Las autoras concluyen que, en todos los manuales analizados los temas que han estudiado «carecen de identificaciones amplias, tanto en las explicaciones como en los ejercicios, ya que se limitan a una o dos líneas, e incluso, en algunas ocasiones, se ofrecen ejemplos del uso cortés de la lengua sin identificarlos explícitamente como tales» (Bani Sara y Nevado Almudena, 2004). Nuria Pérez (1997) analiza el vocabulario que aparece en diferentes libros, y en concreto estudia la aparición y el uso de los colores en los manuales de E/LE. La autora llega a la conclusión de que ninguno de los manuales analizados «ha tenido en cuenta el número de presentaciones y realizaciones de su léxico cromático, y por tanto no ha tratado de aumentarlo de forma regular teniendo en cuenta las necesidades de expresión de los alumnos» (Nuria Pérez, 1997: 642). Sierra María (1991: 119-125) analiza el papel de la mujer en los manuales de español para extranjeros, con el propósito de comprobar la correspondencia de los contenidos culturales que aparecen en la figura de la mujer con un reparto sociocultural real. Para ello, la autora hace un recuento de todos los personajes femeninos que aparecen dibujados representando diferentes profesiones, y posteriormente repasa las frases que aparecen junto a las imágenes y las que se utilizan en la enseñanza y práctica de la gramática. Al final del estudio, la autora efectúa un análisis de las situaciones y contextos culturales en los que aparece la mujer sola o acompañada, ya sea con otra persona o en grupo, y acaba concluyendo que «nos enfrentamos con unos manuales en los que se condensan múltiples realidades que tanto alumnos como profesores tenemos que ir desglosando poco a poco en el trabajo diario» (Sierra María, 1991: 125).

Podemos ver que, en general, todos los análisis realizados a los manuales de español para extranjeros demuestran que este material didáctico no se ajusta a las distintas realidades socio-lingüísticas de los aprendices, y a veces parece que tampoco a la propia realidad de la lengua española. 


\section{Método}

\subsection{Objetivos}

Para llevar a cabo esta investigación, nos hemos planteado las siguientes preguntas que guían nuestro trabajo de investigación: ¿Qué importancia tiene la incorporación de una $\mathrm{u}$ otra cultura en la enseñanza de E/LE?; ¿Qué aspectos culturales se transmiten a través de las entradas encontradas en los cinco manuales?; ¿Se han tenido en cuenta los culturemas argelinos, o algunos de ellos, al elaborar los manuales de E/LE?

Con la primera pregunta pretendemos saber si es suficiente enseñar sólo la cultura (B) (del país cuya lengua queremos estudiar) para aprender la lengua meta (B), o bien deberíamos incorporar en los manuales la cultura (A) (la cultura propia del alumnado) y contrastarla con la cultura (B) para aprender la lengua meta (B). Con la segunda pregunta se pretende llegar a destacar los culturemas reflejados en las entradas (con la palabra entrada/s se refiere a los textos escritos, fotografías, dibujos y documentos icónicos, etc.) de los cinco manuales que se quiere analizar. Finalmente, con la tercera y última pregunta planteada, se quiere averiguar si al elaborar estos manuales se ha dado importancia a los aspectos culturales argelinos.

La hipótesis de partida de este trabajo de investigación es que los manuales son documentos dinámicos que deben estar sujetos a revisiones periódicas para adaptarse y ajustarse a las necesidades cambiantes de toda comunidad lingüística actual, y despertar la capacidad creativa de los estudiantes. Por lo tanto, un manual de E/LE para ser realmente efectivo, tiene que partir de una transmisión del español realizada desde la premisa del contraste específico con el sistema lingüístico de la lengua de los estudiantes $\mathrm{y}$, por ende también a partir de un contraste cultural, de modo que las situaciones cotidianas que sirven para presentar determinadas estructuras lingüísticas deben contemplar la realidad cultural de ambos países.

\subsection{Instrumento}

Águila Torres (2007: 122-128), en su trabajo de investigación, describe con claridad una serie de pautas para suscitar reflexiones para quienes trabajan profesionalmente en el campo del análisis de materiales didácticos. Para ello, ofrece unas parrillas analíticas que nos ayudarán a identificar cada manual y a evaluar los objetivos y los contenidos deseados y planteados en cada uno de ellos.

En este estudio, cuando nos referimos a lo cultural estamos haciendo referencia a aquellos aspectos que se tienen que enseñar en los manuales de E/LE, que forman parte del material utilizado por el Instituto Cervantes de Argel hasta el curso $2011^{2}$, que permiten y llevan al alumnado argelino a adquirir una buena competencia comunicativa; y a aquellos aspectos que le hacen reflexionar sobre su propia cultura y compararla con la cultura hispana. Aplicamos el concepto de culturema al estudio de los manuales de E/LE para abordar mejor los aspectos culturales presentes en aquellos que se pretende analizar. Los culturemas son útiles para la comparación de dos culturas, que pueden o no concordar. Tal como señala Vermeer, citado por Nord Christiane (1997: 34): «un fenómeno social de una cultura $\mathrm{X}$ que es entendido como relevante por los miembros de

\footnotetext{
${ }^{2} \mathrm{http}: / /$ argel.cervantes.es/es/cursos_espanol/cursos_generales_espanol/cursos_generales_espanol.htm [fecha de consulta: 29/03/2011].
} 
esa cultura, y que comparado con un fenómeno correspondiente de una cultura Y, resulta ser percibido como específico de la cultura $\mathrm{X} »$. Dicho de otro modo, consideraremos que un culturema es aquella unidad cultural identificativa, que se puede destacar en los cinco manuales de E/LE, y que refleja lo normal y lo cotidiano en la vida real.

Para la elaboración del corpus, se han analizado cinco manuales, en concreto el libro del alumno de diferentes niveles y de distintas ediciones:

1. Nuevo ELE (2009): Nivel Inicial 1. Escrito por Virgilio Borobio con la colaboración de Ramón Palencia. Editorial: Grupo SM.

2. Nuevo ELE (2010): Nivel Inicial 2. Escrito por Virgilio Borobio con la colaboración de Ramón Palencia, Editorial: Grupo SM.

3. Gente 2, (2004): Autores: Ernesto Martín y Neus Sans. (nivel B1: libro del alumno). Editorial: Difusión.

4. Abanico: nueva edición (2010) (nivel B2: libro del alumno). Elaborado por: M.

D. Chamorro, G. Lozano, P. Martínez, B. Muñoz, F. Rosales, J. P. Ruiz Campillo y G. Ruiz. Editorial: Difusión.

5. El Ventilador: Curso de español de nivel superior, (2006) (nivel C1). Escrito por: María Dolores Chamorro, Gracia Lozano, Aurelio Ríos, Francisco Rosales, José Plácido Ruiz y Guadalupe Ruiz. Editorial: Difusión.

\subsection{Procedimiento de recogida y análisis de datos}

Para analizar aquellos culturemas que aparecen en los manuales objeto de estudio, se ha diseñado un sistema clasificación en el que se han recogido los posibles puntos relevantes para el análisis de los manuales. Según Krippendorff Klaus (1990: 77): «en el análisis de contenido, los datos emergen por lo general a partir de formas simbólicas complejas, enunciadas en un lenguaje espontáneo». En estas formas se deben cumplir ciertos requisitos: los fenómenos de interés deben distinguirse y dividirse en unidades que pueden presentarse en una cantidad tan grande que no permita un manejo fácil, y cada unidad debe codificarse y describirse en formas analizables (Krippendorff Klaus, 1990: 77).

A continuación, se presenta un resumen del esquema de temas creado específicamente en esta investigación para clasificar los culturemas que aparecen en los manuales analizados:

1. Clasificación según la temática sociocultural:

En esta clasificación nos centramos en seis dimensiones:

a. Conocimientos generales de los países hispanos y de Argelia;

b. Antecedentes y protagonistas del pasado y del presente ;

c. Productos y creaciones culturales;

d. Condiciones de vida y organización social;

e. Relaciones interpersonales; y

f. Identidad colectiva y estilo de vida, en los países hispanos y Argelia.

2. Clasificación según la tipología de la entrada: 
En este apartado nos limitaremos a analizarlas entradas destacadas por la tipología de cada una de ellas, siguiendo la clasificación que se presenta a continuación: documentos icónicos, fotografías y dibujos o gráficos; textos escritos.

3. Clasificación según el grado de relevancia de las entradas:

Los aspectos culturales encontrados en los manuales analizados en la presente investigación han sido clasificados en tres grupos según el grado de relevancia del culturema en la cultura argelina: "Irrelevante", no se destaca ninguna relevancia ni de choque ni de coincidencia; "Relevante", sí que se puede encontrar una relevancia de choque cultural o de coincidencia, para referirse a aquellos aspectos culturales que tienen un origen tanto en tradiciones como en cambios sociales, etc.; y "Muy relevante", se nota una gran relevancia, para referirme a los aspectos que tienen origen más bien religioso, sobre todo los que se caracterizan por la prohibición social (control social) y religiosa (tema de Halal y Haram).

Para determinar si los materiales didácticos que se han analizado se adecuan a las necesidades de los alumnos argelinos residentes en Argelia, se ha seguido las pautas planteadas en el Marco Común Europeo de Referencia para las lenguas (MCER). Estos pasos, según Bernao Rueda (1994: 84), serán los siguientes:

1. Análisis de todas las lecciones de cada serie;

2. Recopilación de las referencias a los temas, las situaciones y las funciones;

3. Representación de los resultados en cuadros.

A partir de esta clasificación y las pautas creadas por MCER, se ha elaborado una ficha que servirá, por tanto, para recoger y clasificar cada uno de los culturemas considerados relevantes para la investigación. La ficha consta de las siguientes entradas:

\begin{tabular}{|c|c|}
\hline $\begin{array}{l}\text { Localización: M.... ref.:.... Unidad:.... Página:.... } \\
\text { Temática sociocultural de las entradas: } \\
\text { Dimensiones: }\end{array}$ \\
\hline $\begin{array}{c}\text { Tipo de la } \\
\text { entrada }\end{array}$ \\
\hline Variables & \\
\hline $\begin{array}{c}\text { Abanico } \\
\text { espacial }\end{array}$ \\
\hline $\begin{array}{c}\text { Finalidad } \\
\text { cultural }\end{array}$ \\
\hline $\begin{array}{c}\text { Grado de } \\
\text { relevancia }\end{array}$ \\
\hline $\begin{array}{c}\text { Descripciones } \\
\text { observaciones }\end{array}$ \\
\hline
\end{tabular}

Tabla 1. Ficha de análisis usada en el estudio.

Para localizar cualquier entrada que contenga uno o más aspectos culturales hemos optado por poner, en primer lugar, el código designado a los manuales (M1, M2, M3, M4 o M5); en segundo lugar, el número de la ficha (ref. :...); luego, en qué unidad o sesión se encuentra en el manual, además de en qué página y por último el número de la actividad o ejercicio. 
Asimismo, nos ha parecido razonable crear un apartado para destacar las entradas de los culturemas integrados en los manuales analizados. En otras palabras, las entradas se han clasificado según:

1. Temática sociocultural de la entrada;

2. Tipo de la entrada: sus distintos soportes, como textos escritos y gráficos;

3. Variables: se agrega este apartado a la ficha de análisis para ser preciso en la descripción de la entrada, ofreciendo más detalles sobre los aspectos culturales que aparecen en ella;

4. Abanico espacial: para indicar si se refiere a España, América Latina, Argelia y/o sin indicio;

5. Finalidad cultural: en este apartado se menciona la relevancia en la cultura hispana o en la de Argelia, o en ambas culturas o en ninguna;

6. Grado de relevancia: en el análisis de los cinco manuales se ha usado este término en tres grados:

1. Irrelevante,

2. Relevante y

3. Muy relevante.

7. Descripciones y observaciones: en este apartado se describe la actividad, y se contrastan los aspectos culturales que aparecen en ella con los del alumnado argelino.

\section{Resultados}

Después de analizar los 5 manuales citados y descritos anteriormente, ha de mencionar que hemos podido destacar 1045 entradas que tienen uno o más aspectos culturales.

\begin{tabular}{cccc}
\hline & & \multicolumn{2}{c}{ Tipo de la entrada } \\
\hline Manual & Número de entradas & Texto escrito & Gráficos \\
\hline M1 & 151 & 64 & 87 \\
\hline M2 & 180 & 57 & 123 \\
\hline M3 & 258 & 89 & 169 \\
\hline M4 & 246 & 107 & 70 \\
\hline M5 & 210 & 140 & 588 \\
\hline
\end{tabular}

Tabla 2. Tipo de las entradas encontradas en los manuales (M1, M2, M3, M4 y M5)

Partiendo de los resultados obtenidos se puede ver que en los cuatro primeros el tipo de 
las entradas más numerosas es el correspondiente a "Gráficos", que predomina con porcentajes superiores al $56 \%$, mientras que las entradas de tipo "Textos escritos" alcanzan tan sólo el $44 \%$, esto explica lo que afirma Dondis Donis:

Al ver, hacemos muchas cosas más: experimentamos lo que está ocurriendo de una manera directa; descubrimos algo que nunca habíamos percibido o posiblemente ni siquiera mirado; nos hacemos conscientes, a través de una serie de experiencias visuales, de algo que eventualmente llegamos a reconocer y saber; contemplamos cambios mediante la observación paciente (1979: 10).

Los gráficos juegan, por su carácter visual inmediato al transmitir el mensaje, un papel informativo y comunicativo. Las entradas de esta tipología no requieren mucha energía para que la mente reciba y conserve la cantidad que sea de las unidades de información en una fracción de segundo, captando el significado del mensaje o no. Esta información recibida visualmente es aglomerada de manera segura y rápida, y luego recordada y usada, en muchos casos, de manera inconsciente y sin esfuerzo.

A partir de las entradas recogidas en esta investigación se han podido destacar 371 de las que contienen uno o más culturemas, limitadas por la clasificación según el grado de relevancia en culturemas relevantes y otros muy relevantes como se explica en la tabla siguiente:

\begin{tabular}{cccccc}
\hline & & Tipo de la entrada & & Grado de relevancia & \\
\hline Manual & $\begin{array}{c}\text { Número de las } \\
\text { actividades que } \\
\text { contienen Culturemas }\end{array}$ & Texto escrito & Gráficos & Relevante & Muy relevante \\
\hline M1 & 51 & 13 & 38 & 37 & 14 \\
\hline M2 & 91 & 23 & 68 & 71 & 20 \\
\hline M3 & 71 & 19 & 52 & 60 & 11 \\
\hline M4 & 70 & 29 & 41 & 42 & 28 \\
\hline Total & 88 & 59 & 29 & 67 & 94 \\
\hline
\end{tabular}

Tabla 3. Número de las actividades que contienen culturemas y su grado de relevancia

El análisis de estas fichas nos permite clasificarlas en 6 bloques temáticos, los cuales a su vez se encuentran subdivididos en 38 ámbitos culturales que contienen los culturemas que aparecen en los manuales. 


\begin{tabular}{|c|c|}
\hline Bloques & Áreas y ámbitos culturales \\
\hline $\begin{array}{l}\text { 1. Conocimientos generales de los paí- } \\
\text { ses hispanos y Argelia }\end{array}$ & $\begin{array}{c}\text { Geografía física: climas, particularidades geográficas } \\
\text { Población: pueblos de los países hispanos, del mediterráneo, corrientes } \\
\text { migratorias, etc. } \\
\text {. Gobierno y política } \\
\begin{array}{c}\text { Organización territorial y administrativa: demarcación territorial y ad- } \\
\text { ministrativa; ciudades y pueblos } \\
\text {. Economía e industria } \\
\text {. Educación } \\
\text {. Medios de comunicación } \\
\text {. Medios de transporte } \\
\text {. Religión } \\
\text {. Política lingüística }\end{array}\end{array}$ \\
\hline
\end{tabular}

2. Acontecimientos y protagonistas del . Acontecimientos y personajes históricos y legendarios: Hitos históripasado y del presente cos; personajes legendarios

\begin{tabular}{cc}
\hline $\begin{array}{c}\text {. Literatura y pensamiento } \\
\text {. Musica } \\
\text { los países hispanos y de Argelia }\end{array}$ & . Cine y artes escénicas \\
& . Arquitectura \\
& . Artes plásticas \\
\hline
\end{tabular}

Identificación personal

La unidad familiar: concepto y estructura

Calendarios: días festivos, horarios y ritmos cotidianos

. Comidas y bebidas

4. Condiciones de vida y organización social Indumentaria

Actividades de ocio, hábitos y aficiones

. Medios de comunicación e información

La vivienda: características y tipos; acceso y y mercado

. Medicina y sanidad

\begin{tabular}{l} 
5. Relaciones interpersonales \\
6. Identidad colectiva y estilo de vida $\quad \begin{array}{c}\text {. En el ámbito personal y público } \\
\text {. En el ámbito profesional }\end{array}$ \\
$\begin{array}{c}\text {. Identidad colectiva: sentido de pertenencia a la esfera social } \\
\text {. Tradición y cambio social }\end{array}$ \\
\hline
\end{tabular}

Tabla 4. Clasificación de las entradas en bloques subdivididos en áreas y ámbitos culturales.

\subsection{Conocimientos generales de los países hispanos y Argelia}

Tras analizar las entradas clasificadas por su grado de relevancia en relevantes y muy relevantes del total de 371 conseguidas, se han podido destacar y clasificar un total de nueve ámbitos culturales relacionados con los conocimientos generales existentes en ambas culturas: 1.1 Topónimos, lugares Patrimonio de la Humanidad, monumentos geográficos, artístico-históricos, 1.2. Situación lingüística de la sociedad, el consumo cultural y el consumo mediático, el léxico de colores y de silencio, el lenguaje corporal y la gesticulación, 1.3. Organización territorial de España (mapa), comunidades autónomas y división provincial, diversas lenguas oficiales, 1.4. Lenguaje no verbal y gesticulación, significado de los gestos de mano, tipo de programas de TV, radio, prensa, etc., conocer 
gente a partir de los anuncios en los periódicos, 1.5. Mujeres/chicas trabajan como dependientas, 1.6. Grupos étnicos (árabes e imazighen), 1.7. Actos/fiestas y creencias religiosos, creer en Alláh/Dios/Jesús/el profeta Muhámmad, fiestas conmemorativas y tristes, el significado de las fiestas religiosas, 1.8. Compra y venta de billetes, horarios de transportes públicos y privados, viajes dentro del mismo país, 1.9. Educación, evaluación y exámenes.

\subsection{Acontecimientos y protagonistas del pasado y del presente}

En este apartado del estudio, se han podido destacar y clasificar, de las 371 entradas encontradas, dos ámbitos culturales relacionados con los acontecimientos históricos y los personajes legendarios que aparecen en ambas culturas: 2.1. Personajes históricos y legendarios de los países hispanos y de Argelia, 2.2. Hitos y acontecimientos históricos de los países hispanos y de Argelia.

\subsection{Productos y creaciones culturales de los países hispanos y de Argelia}

En éste bloque, se distinguen un total de cuatro ámbitos culturales relacionados con los productos y creaciones culturales existentes en ambas culturas: 3.1. Cantantes españoles e internacionales y grupos musicales de mucho éxito, 3.2. Los directores de cine, actores y actrices, películas nacionales e internacionales, 3.3. Los pintores y escultores y sus obras maestras, pintura religiosa, 3.4. Los grandes autores, generaciones y obras literarias, las corrientes literarias, refranes y frases hechas.

\subsection{Condiciones de vida y organización social}

Se han podido observar y clasificar un total de catorce ámbitos culturales relacionados con las condiciones de vida y la organización social existentes en ambas culturas: 4.1. Nombres y apellidos, el nombre de Mohamed (Muhámmad), 4.2. La vivienda, casa de la gran familia, decoración, acceso a la vivienda, 4.3. Los horarios públicos en España, calendario y días de la semana, 4.4. Los malos hábitos (desde la perspectiva/ética social), 4.5. Actividades de ocio, mujer y deporte al aire libre (montar en bicicleta, etc.), actividades/salir el fin de semana, los malos hábitos, actividades cotidianas relacionadas con la mujer, cotillear, loterías, 4.6. Ropa femenina del día a día, ropa femenina deportiva, 4.7. Tipos de establecimientos (bares, cafeterías, etc.), 4.8. Comida y bebida halal; comida y bebida haram, horarios de comidas principales, 4.9. Mujer y trabajo, hombre y trabajo, 4.10. Celebrar una boda, celebrar un cumpleaños, 4.11. Cotillear, mujeres fumando, 4.12. Medicina contemporánea, medicina y remedios caseros (el uso de ajo), 4.13. Juegos y lotería, 4.14. Tiendas online.

\subsection{Relaciones interpersonales}

Se han podido destacar y clasificar un total de seis ámbitos culturales relacionados con las relaciones interpersonales existentes en ambas culturas: 5.1. Saludos entre sexos, contacto físico entre sexos, ligar y conocer chicas, relaciones entre sexos en lugares públicos, 5.2. Relaciones de amistad, 5.3. Relaciones de amistad y entre parejas, 5.4. Relaciones entre sexos y de amistad, 5.5. La gran familia, relaciones entre generaciones: 
cortesía, tratamiento, la unidad familiar: concepto y estructura, la gran familia, 5.6. Relaciones entre parejas.

\subsection{Identidad colectiva y estilo de vida}

Se presentan un total de tres ámbitos culturales relacionados con la identidad colectiva de los pueblos y su estilo de vida, comunes en ambas culturas, que han sido clasificados según la tabla de dimensiones mencionada anteriormente: 6.1. Fiestas, ceremonias y celebraciones, 6.2. Tradición y cambios sociales, 6.3. Identificación colectiva (valores, creencias y actitudes).

A continuación, se expondrán algunas imágenes de casos paradigmáticos que nos servirán para ejemplificar cómo proceden los manuales y cómo deberían proceder los futuros manuales de E/LE para alumnos argelinos:

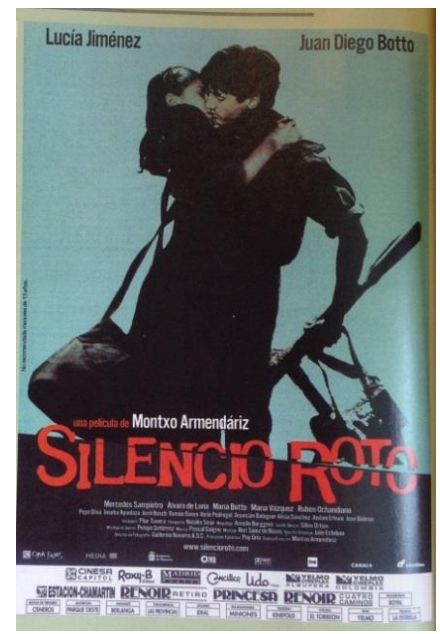

Imagen 1. (M1. ref.: 14. Unidad: 14. Página: 132)

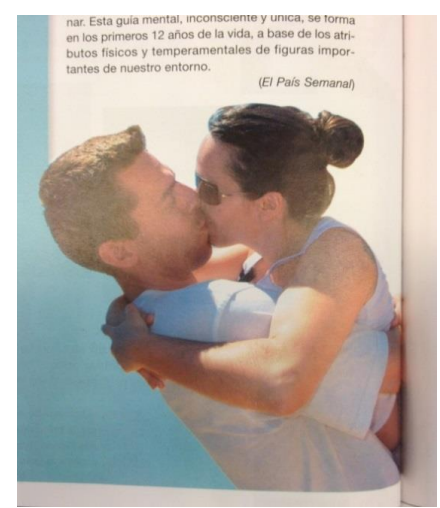

Imagen 3. (M3. ref.: 94. Unidad: 9. Página: 92)



Imagen 2. (M4. ref.: 205. Unidad: 11. Página: 183 [cuadro 5])

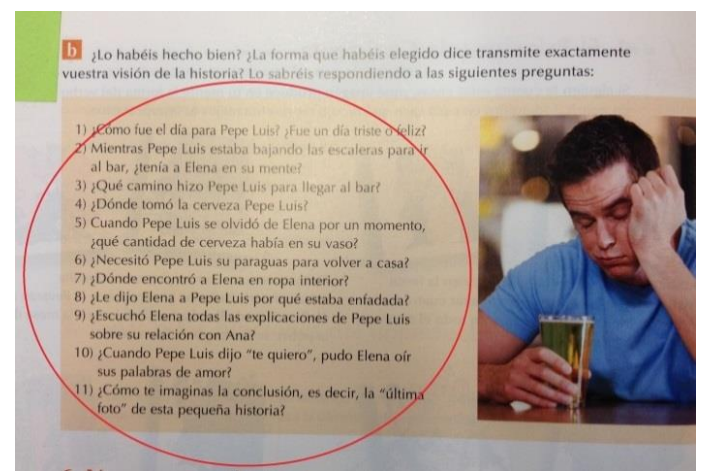

Imagen 4. (M4. ref.: 21. Unidad: 2. Página: 40)

Lo que podemos ver a partir de estas cuatro imágenes, de modo de ejemplo, los autores de los manuales dan por sentada la normalidad de ver imágenes que muestran el contacto físico entre los dos sexos, como en el caso de la portada de la película incluida en la 
actividad de la imagen 1, o en el caso de las escenas íntimas entre parejas, como besarse en la boca y abrazarse en la imagen 3. No obstante, estas imágenes que muestran este tipo de contactos entre los dos sexos generarán un rechazo cultural porque provocan al alumnado argelino, cuyo entorno social y religioso prohíbe estos hechos y estas posturas que hieren la sensibilidad colectiva de la sociedad. En la sociedad argelina, generalmente, no se pueden ver películas con escenas de sexo, de bebida alcohólica, etc. con los padres, o con los familiares en general, porque se considera una falta de pudor. La religión prohíbe tratar a la mujer como instrumento sexual, verla desnuda parcial o completamente, o en escenas eróticas.

En la misma línea de los ejemplos anteriores acerca de la relación entre los dos sexos, encontramos otro tipo de actividades que tratan el tema de la vestimenta mediante la incorporación de frases y expresiones, el caso de la image 4. Entre estas frases y expresiones nos llaman la atención unas cuantas que podrían resultar inapropiadas en el entorno del alumnado argelino, como hablar de la ropa interior, del nudismo en las playas, por escrito o insertando imágenes como la del ejemplo de la imagen 2, etc., porque en su sociedad se consideran temas tabú, pues se relacionan con los códigos sociales del colectivo argelino y con la sharîa islámica.

En todo lo encontrado en los 6 bloques se constata el predominio absoluto de la presentación de la cultura española e iberoamericana, lo que no es sorprendente en absoluto habida cuenta que los manuales, como ya se ha detallado anteriormente, no han sido redactados para un usuario específico argelino. Según lo que acabamos de exponer, en la presentación de lo cultural tendría que primar la presentación explícita en lugar de la implícita. La presentación de los hechos culturales se transmite tanto explícitamente como implícitamente, con predominio de una presentación implícita del material cultural, que suele realizarse a través de mecanismos gráficos. El alumnado argelino necesita una clarificación explícita de los hechos culturales que ve expuestos a lo largo del manual. Al no darse tales explicaciones, el alumno argelino puede reinterpretar mal los hechos culturales españoles, produciéndose de este modo malentendidos culturales que pueden fosilizarse en el estudiante y originar en él visiones distorsionadas de los hechos culturales españoles presentados, lo que a su vez puede llevar a una visión sesgada de buena parte de la realidad cultural española.

\section{Puntos de conflicto con lo social}

Tras analizar esta clasificación, exponemos con brevedad cuáles son los dos puntos de conflicto principales encontrados:

\subsection{El control social en la sociedad argelina}

Entre los mayores códigos sociales que influyen en la sociedad argelina encontramos lo que se denomina el control social, que hace referencia a aquellas normas y regulaciones de distintos tipos establecidas por los miembros de la sociedad desde hace décadas, para mantener un cierto orden y convivencia entre los individuos. El control social ejercido sobre un individuo argelino está siempre influido por el Islam, una religión plurisecular en Argelia, y por supuesto la primera institución en ejercerlo es la propia familia que tiene, junto con la religión, un especial peso en la exteriorización de sus actitudes y pensamientos. Este tipo de control social no existe en una sociedad como la española, en 
la que las relaciones entre individuo, familia y sociedad se basan en otras premisas y condicionantes. La consecuencia directa de esto último es que los manuales de lengua española presentan todas las situaciones de interrelación o interacción social desde la perspectiva española, lo que en sí mismo sería correcto, si se tuviera en cuenta que dichas interacciones no son posibles o deben realizarse de modo muy diferente en Argelia, por lo que el estudiante de lengua española no puede identificarse plenamente con los protagonistas de la interacción social descrita en los manuales de lengua.

\subsection{Las creencias e interpretaciones religiosas (en el entorno argelino)}

El Islam es una religión que abarca todos los dominios de la vida de los creyentes, quienes, por lo tanto, delante de cada acto que quieran realizar se tienen que preguntar: ¿está permitido o es lícito (halal)?, ¿está prohibido o es ilícito (haram)? De todo ello se desprende que en Argelia, como en el resto de los países del Magreb, lo religioso se entrelaza fuertemente con lo social y, por ende, con lo lingüístico. Esta doctrina da mucha importancia a las tradiciones, y este hecho es el que ha llevado a buena parte de la comunidad magrebí a no distinguir entre lo que son tradiciones propiamente dichas y lo que son normas religiosas, dado que las tradiciones se suelen interpretar desde una óptica religiosa. En los manuales de E/LE analizados, los autores dan implícitamente por sentada la universalidad de las creencias religiosas (es decir, cristianas) del mundo español, y este hecho ha llevado a crear manuales con representaciones de los valores, actitudes cotidianas, de indumentaria, de bebida i/o comida, de representación de las fiestas religiosas, comportamientos sociales, etc., que pueden llevar a una reacción negativa a los aprendices argelinos de español, principalmente por desconocimiento de una cultura que puede ser tan distinta a la suya.

\section{Discusión y conclusiones}

A continuación, partiendo de todo lo dicho anteriormente, se intentará en la medida de lo posible, responder a las preguntas de investigación planteadas al inicio de este artículo.

\section{1. ¿Qué importancia tiene la utilización de una u otra cultura en la enseñanza de E/LE?}

Consideramos que desconocer las pautas socioculturales de la lengua meta desde la percepción consciente e inconsciente del alumnado argelino, y sin contrastarlas con las propias limitará la comprensión, el entendimiento y el equilibrio entre ambas. Este hecho podría provocar un rechazo y un choque cultural en el alumnado argelino, el usuario de estos manuales de E/LE, lo cual nos lleva a confirmar que es necesario incorporar, en los manuales de E/LE dirigidos a argelinos o a cualquier aprendiz de ELE, los culturemas del entorno del alumnado, contrastándolos con los culturemas del entorno hispano-occidental para aprender la lengua española como lengua extranjera. De modo que el método tiene que ser un transmisor de unos conocimientos culturales españoles en general, pero, siempre teniendo en cuenta la misma realidad en la cultura del aprendiz, es decir, no se puede exponer la cultura española sin proporcionar información suficiente que podría servir de gran ayuda para saber interpretarla correctamente, y sin explicarla en contraste con la otra cultura, independientemente de que una parte del manual transcurra 
directamente en el entorno del aprendiz.

\section{2. ¿Qué aspectos culturales se transmiten a través de las entradas encontradas en los cinco manuales?}

A partir del análisis exhaustivo de los cinco manuales, se ha podido comprobar que los culturemas relevantes y muy relevantes son transmitidos de manera tanto explicita como implícita mediante el uso de dibujos o imágenes. Esto demuestra que la función más común otorgada a las imágenes usadas en los manuales de E/LE no era sólo decorativa, sino que transmiten muchos mensajes, si bien muy pocas veces las ilustraciones desempeñan un papel didáctico o se aprecia en ellas una preocupación por ser adecuadas y relevantes en la cultura del mundo hispano-occidental.

En los cinco manuales analizados prácticamente no hay ninguna alusión al mundo arabomusulmán y las referencias culturales se ciñen a la cultura occidental a la que pertenece España. Por ello, pensamos que esta escasez podría resultar un poco limitadora y no muy motivadora para el alumnado, puesto que si se desenvuelve en una situación real de comunicación en español, tendrá que explicar su entorno, su mundo, su cultura, etc. Por ello es preciso resaltar una vez más la necesidad de hacer participar al alumnado, que forme parte de los manuales de E/LE y hacerle sentir identificado con los mismos, porque es el alma del contenido, introduciendo culturemas que le son propios, de manera paralela a los culturemas del entorno hispano incorporados en los manuales de E/LE destinados a Argelia.

\section{3. ¿Se han tenido en cuenta los culturemas argelinos, o algunos de ellos, al elaborar los manuales de E/LE?}

Al no dar cabida explícita e implícita en los cinco manuales de E/LE objeto de esta investigación, a temas y aspectos culturales, no se les ofrece la oportunidad de reflexionar de manera analítico-crítica sobre los posibles contrastes y similitudes entre la cultura extranjera y llegar a compararla con la suya, lo cual podría limitar su acceso al nivel de competencia deseado. Por otra parte, tras el análisis de los cinco manuales de E/LE con los que se ha trabajado en esta investigación, consideramos que los autores no han tenido en cuenta lo que podrían provocar este tipo de entradas, porque muchos de estos temas se consideran tabúes, y no son aceptables ni desde un punto de vista social ni religioso, y por lo tanto son inadecuados e inapropiados en el manual de E/LE destinado a Argelia. Ello es debido al hecho que están dirigidos a un alumnado con una idiosincrasia muy diferente, con unos intereses y necesidades totalmente distintos a los planteados o imaginados por los autores, y en el peor de los casos están elaborados con el objetivo de ser universales, para poder ser utilizados por estudiantes de cualquier país del mundo y por tanto de culturas muy dispares. Sin embargo, esta "universalidad" se restringe a la cultura occidental y no tiene en cuenta cualquier otra. Aún más, la mayoría de las imágenes que reflejan los temas y situaciones que presentan algunos culturemas (en el hotel, en la estación de autobuses o de tren, haciendo deporte, en el restaurante o en el bar, en una fiesta, etc.), la mayoría, si no todas, resultan un poco ajenas al entorno y a la cultura del colectivo argelino, porque muestran unos culturemas que pertenecen a la cultura hispana y a la occidental-europea, con los que difícilmente se siente identificado el alumnado argelino, no inmerso en el entorno de la cultura hispana. 


\section{Consideraciones finales}

Estamos convencidos que no existe un manual de lengua extranjera perfecto, que se adecue al cien por cien a las necesidades de los alumnos, estudiantes de la lengua española como lengua extranjera. Ello es debido, al hecho de que cuando se elaboran estos manuales, los autores tienen en mente un "alumno imaginario", con unas necesidades supuestas por ellos y desde la perspectiva de su entorno, lo cual, no sólo no siempre coincide con la realidad sino que podría provocar un malentendido que podría llevar a un choque y un rechazo cultural por parte del alumnado receptor y usuario del manual de E/LE.

Este hecho nos lleva a destacar la universalidad de los manuales usados para enseñar el Español como Lengua Extranjera en Argelia (y por ende en cualquier país donde se estudie español como lengua extranjera), lo cual nos lleva a preguntarnos si al final del curso o del nivel deseado este alumno podrá ser un agente social capaz de mediar entre culturas, de reconocer las diferencias, de percibir las unas en contraste y relación con las otras, y de establecer una comunicación que tenga en cuenta tales semejanzas y diferencias. Para lograrlo se trataría de acercar una cultura, la española, a otra cultura, la del aprendiz. Y no hay nada mejor para lograr este acercamiento, que hacer que los estudiantes sean conscientes de las mínimas diferencias culturales existentes. Es mejor hacerles conscientes de modo explícito que implícito, ya que como hemos visto, los manuales de tipo universal no logran involucrar al alumnado argelino para que se sienta identificado con ellos.

\section{Bibliografía:}

Águila Torres, J. R. (2007). «Las actividades en los manuales de pronunciación de Inglés como lengua extranjera». Biblioteca Phonica, 6.

Ares ÁlidA, M. (2008). Análisis tipológico, pragmático y lingüistico de los textos de unidades didácticas específicas de los manuales de E/LE. Barcelona: Universitat de Barcelona.

BANI, S. \& NEVADO, A. (2004). «Aproximación a la cortesía verbal en manuales de E/LE». Artifara, 4, sezione Monographica. Recuperado el 28/6/2020, de: https://www.researchgate.net/publication/

BARALO MARTA (2003). «Analizar materiales desde una perspectiva psicolingüística: ¿Qué aprendemos y con qué?». XII Encuentro práctico de profesores de ELE. IH Difusión. Barcelona.

BERNAO RUEDA, M. J. (1994). Análisis de cuatro manuales para la enseñanza del español lengua extranjera. REALE, vol.2, pp. 79-114.

Byram, M. (1989). Cultural Studies in Foreign Language Education. Clevedon: Multilingual Matters Ltd.

Dondis Donis, A. (1976). La sintaxis de la imagen, Colección GG Diseño. Recuperado el 16/03/2014, de https://www.google.es/url?sa=

GARCÍA, P. (1999). «El enfoque internacional en la enseñanza de español a inmigrantes». Carabela, vol. 45, pp. 107-124. 
GARCÍA SALAZAR, V. (2004). «Acercamiento crítico a la selección objetiva de contenidos léxicos en la enseñanza de ELE». ELUA, vol.18, pp. 243-273.

KriPPENDORFF, K. (1990). Metodología de análisis de contenido. Teoría y práctica. Barcelona: PAIDÓS.

Morte BARCELÓ, L. (2003-2005). Los estereotipos de género en los manuales de ELE. Estudio de las representaciones de varones y mujeres en cuatro libros de texto publicados en España entre 2003-2004 (Memoria de Máster). en Máster de Formación de Profesores de ELE. Barcelona: Universitat de Barcelona.

NAVArro Gómez, L. (2006-2008). El componente cultural en los manuales de ELE (Nivel A1 y A2) para estudiantes de lengua Alemana (Memoria de Máster). Máster de Formación de Profesores de ELE. Barcelona: Universitat de Barcelona.

NORD, C. (1997). Translating as a Purposeful Activity: Functionalist Approaches Explained. Manchester: St. Jerome Publishing.

PÉREZ DE LA CRUZ, N. (1997). «Análisis léxico de manuales de español para extranjeros». ASELE Actas VIII, pp. 631-643.

POTTIER BERNARD (1993). «Lenguas y culturas». En Manuel Alvar y Bernard Pottier (coord.), Discursos de Investidura de Doctores "Honoris Causa". Madrid: UNED, pp. 21-54.

Poyatos, F. (1994). La comunicación No verbal: cultura, lenguaje y conversación, Vol. I. Madrid: ISTMO.

RODRÍGUEZ ABELlA, R. M. (2000-2004). El componente cultural en algunos manuales de español para italianos. Recuperado el 19/01/2014, de http://www.ub.edu/filhis/culturele/rosarodriguez.html.

RODRÍGUEZ GARRIDO, M. C. (2005). "Análisis de materiales destinados a la enseñanza del español como lengua extranjera para niños». Glosas didácticas, $n .^{\circ} 13$, pp. 64-79.

SiERRA GALIANO, I. M. (1991). «La mujer en los manuales de español para extranjeros». ASELE Actas III, Centro Virtual Cervantes, pp. 119-125. 